\title{
A Bayesian threshold-linear model evaluation of perinatal mortality, dystocia, birth weight, and gestation length in a Holstein herd ${ }^{1}$
}

\author{
J. M. Johanson, ${ }^{\star}$ P. J. Berger, ${ }^{2}{ }^{2}$ S. Tsuruta, $\dagger$ and I. Misztal† \\ *Department of Animal Science, lowa State University, Ames 50011-3150 \\ †Department of Animal and Dairy Science, University of Georgia, Athens 30602-2771
}

\section{ABSTRACT}

The objective of this research was to estimate genetic parameters for a multiple-trait evaluation of dystocia (DYS), perinatal mortality (PM), birth weight (BWT), and gestation length (GL) in Holsteins. The data included 5,712 calving records collected between 1968 and 2005 from the Iowa State University dairy breeding herd in Ankeny. The incidence of PM was $8.8 \%$ and that of DYS $28.8 \%$; mean BWT was $40.5 \mathrm{~kg}$, and GL was 279 d. A threshold-linear animal model included the effects of year, season, sex of calf, parity, sire group, direct genetic, maternal genetic, and maternal permanent environment. Direct heritabilities for DYS, PM, BWT, and GL were 0.11 (0.04), 0.13 (0.05), $0.26(0.04)$, and $0.51(0.05)$, respectively. Maternal heritabilities were $0.14(0.04), 0.15(0.03), 0.08$ (0.01), and 0.08 (0.02), for DYS, PM, BWT, and GL, respectively. The heritabilities are the posterior means of the Gibbs samples with their standard deviations in parentheses. The direct genetic correlation between PM and DYS was estimated at 0.67 (0.19), whereas the maternal genetic correlation was $0.45(0.16)$. Direct and maternal PM and DYS are partially controlled by the same genes. Selection on only calving ease is not sufficient to control PM. With moderate genetic correlations between all 4 traits, BWT and GL should be included with DYS and PM in an evaluation of calving performance.

Key words: birth weight, dystocia, gestation length, perinatal mortality

\footnotetext{
Received December 11, 2009.

Accepted September 21, 2010.

${ }^{1}$ Journal Paper of the Iowa Agriculture and Home Economics Experiment Stations, Ames; Project Number 3538, supported by Hatch Act and State of Iowa Funds.

${ }^{2}$ Corresponding author: pjberger@iastate.edu
}

\section{Perinatal Mortality}

Perinatal mortality (PM) is defined as a stillbirth or death before $48 \mathrm{~h}$ of age. It is quite costly to replace a dead calf, especially a dead heifer calf. Dematawewa and Berger (1997) estimated the value of a male calf to be $\$ 70$ and that of a female calf to be $\$ 150$.

There is ongoing concern about the unfavorable incidence of PM or stillbirth (SB) in Holstein cattle in the United States. The first extensive analysis of producerrecorded field data for PM at a national level identified both phenotypic and genetic changes from 1985 to 1996 (Meyer et al., 2001a,b). First-parity PM increased from $9.5 \%$ in 1985 to $13.2 \%$ in 1996 (Meyer et al., 2001a. Meanwhile, later parity cows had a small increase from 5.0 to $6.6 \%$. Since 1996, the quantity and quality of data suitable for national genetic evaluations has improved substantially. Better identification of service sire and sire of cow are noteworthy enhancements. Higher quality data has made it possible to proceed with implementation of a sire-maternal grandsire model to more specifically address both direct and maternal genetic effects associated with PM (Van Tassell et al., 2003). For Holsteins in the United States, the yearly average incidence of SB from 1980 to 2005 was reported to be 10.5 and $5.9 \%$ in heifers and cows, respectively (Cole et al., 2007a). Despite a wider base of sires with progeny, evidence is lacking for any consistent genetic trend in service sire or daughter SB (Cole et al., 2007a).

\section{Dystocia}

Dystocia (DYS) often leads to PM. Whether or not PM occurs, DYS is an unfavorable trait for dairy producers. A difficult birth can cause trauma both for the cow and the calf. The cow may experience reduced milk production or uterine infection resulting in additional veterinary costs and decreased fertility (Dematawewa and Berger, 1997). A difficult parturition can substantially increase the calf's risk of PM. Dystocia may also contribute to additional management costs for continuous surveillance of parturient cows. 
Van Tassell et al. (2003) reported incidences of DYS (needed assistance, considerable force, and extreme difficulty) of 22.6, 10.4, and $9.7 \%$ for first, second, and later parities, respectively. In Denmark, Hansen et al. (2004b) reported first-parity cows to have an incidence of calving difficulty (without and with veterinarian) at $11.2 \%$. In Sweden, Steinbock et al. (2003) reported incidences of calving difficulty at 8.3 and $4.5 \%$ in first and second parities.

\section{Birth Weight}

McDermott et al. (1992) found that birth weight (BWT) is the most important factor in predicting DYS. As for PM, Berger et al. (1992) noted that Angus calves that are lighter and heavier than average tend to have more PM. Unfortunately, BWT is not commonly measured in field data for Holsteins. Meijering (1984) concludes that the effect of BWT on incidence of DYS is nonlinear but is sometimes mistakenly modeled as a linear effect.

In the United States from 1988 to 2001, a threshold sire model (Djemali et al., 1987) was used for genetic evaluation of sires for calving ease (CE; Berger, 1994), but there was no formal evaluation for PM. In the Iowa State University dairy breeding herd, Johanson and Berger (2003) observed an increasing phenotypic trend in PM, along with a decreasing phenotypic trend in DYS from 1968 to 1999. The inverse relationship between PM and DYS over time implies that the 2 traits are negatively correlated; however, this is opposite of the generally accepted positive phenotypic correlation between DYS and stillbirth. In Denmark, where there has been heavy use of North American Holstein genetics, Hansen et al. (2004b) also found opposing phenotypic trends in which the incidence of stillbirth was increasing but the incidence of calving difficulty was decreasing. However, the genetic trends increased for both traits (Hansen et al., 2004b). These opposing trends may indicate improved management over time to reduce DYS but continued genetic problems in stillbirths. On the other hand, it may indicate that selection on DYS alone is not sufficient to reduce stillbirths in spite of positive genetic correlations. In June 2002, a national evaluation of daughter calving ease (DCE) became available in the United States (Van Tassell et al., 2003; Wiggans et al., 2003). This evaluation for DCE was later expanded to include Brown Swiss and Holstein bulls from purebred and crossbred calvings (Cole et al., 2005). Dekkers (1994) reports that the best breeding strategy for calving ease should include both direct and maternal effects. Steinbock et al. (2003) recommend that sires need to be evaluated for both DYS and stillbirth. By 2007 routine genetic evaluations for stillbirths were available in the United States (Cole et al., 2007a,b).

Even though DYS influences stillbirth, many stillbirths occur without DYS. In Sweden, Steinbock et al. (2003) found that dead calves were born without calving difficulty at a rate of 53 and $33 \%$ from first- and second-parity cows, respectively. In the United States, Meyer et al. (2000) reported incidence of DYS at 39.6 and $61.5 \%$ for first-parity and later parity cows, respectively. The Iowa State University dairy breeding herd had $49 \%$ of stillbirths resulting from unassisted deliveries (Johanson and Berger, 2003). The focus to reduce DYS and BWT has ignored the fact that approximately half of PM cases are unrelated to DYS and large BWT. All possible ways to make reductions in PM losses should be investigated.

This study continues earlier work by Johanson and Berger (2003) that modeled the association among fixed effects accounting for the largest proportion of variation in PM and DYS. The objectives of this study were to estimate the genetic parameters of DYS, PM, BWT, and gestation length (GL).

\section{MATERIALS AND METHODS}

\section{Data Preparation}

The data were collected at the Iowa State University dairy breeding herd in Ankeny, Iowa. This herd was founded in 1968 to study the direct and correlated responses for long-term selection of sires for high and average PTA milk yield. Cows were randomly assigned to 2 groups: high or average milk yield. From 1968 to 1984, cows were mated to bulls selected for either high or average PTA milk yield. In 1984, cows were rerandomized into 2 slightly different groups. From 1984 to the present, cows have been mated to bulls selected for high or average PTA fat plus PTA protein yield. As a result, 5 sire selection groups were defined: foundation animals, high and average milk yield, and high and average fat yield plus protein yield. No voluntary culling for production, DYS, PM, BWT, or GL occurred from 1968 to 2005.

We did not include twin calves in this analysis, because we were primarily interested in what causes single-born calves to die or be difficult to deliver. Twins, however, are noted to have higher incidences of PM and DYS than singletons (Johanson et al., 2001). Birth weights were recorded at birth to the nearest pound by using a scale available at the farm. Records of BWT (kg) and GL (d) outside $3 \mathrm{SD}$ were omitted. After these omissions, the data set contained 5,712 records of calves being born from 2,256 cows (approximately 2.5 calving records per cow). Calving years range from 1968 to 2005. Because 
so few calves were born in 1968 and 2005, births in 1968 to 1969 were combined and births in 2004 to 2005 were combined. The smallest number of calvings (43) occurred in 1968 to 1969; the largest number of calvings (211) occurred in 1996. In general, the number of calvings increased from the foundation of the herd in 1968 until 1978, when the number of calvings leveled off to around 180 for each year after 1978. Season was classified as summer (April to September) and winter (October to March). Parity was combined into 2 levels: primiparous (1) and multiparous (2 to 10). As a routine management practice, heifers were required to reach 14 mo of age and a weight of $340 \mathrm{~kg}$ before they were bred. A description of the data for incidence of PM and DYS and mean BWT and GL by levels of fixed effects is given in Table 1.

The 5 DYS categories used in the Iowa State University dairy breeding herd were established when the herd was founded in 1968. Unfortunately, our categories do not correspond directly with the categories used in the more recently applied US national data recording scheme for DYS (Van Tassell et al., 2003; Wiggans et al.,. 2003; Cole et al., 2005, 2007a,b). The best way to align the 2 recording systems was to condense the 5 DYS categories down to only $2(0=$ unassisted, and $1=$ assisted, including all births assisted by manual pull, chain pull, jack, or caesarean). The protocol for providing assistance was to give the cow $2 \mathrm{~h}$ without assistance after the appearance of the calf's feet. If the cow did not make progress after the 2 -h waiting period, assistance was then provided. There was no selection of bulls, cows, or heifers based on their evaluation for DYS. Perinatal mortality was defined as $0=$ alive or 1 $=$ dead within $48 \mathrm{~h}$ after parturition.

\section{Threshold-Linear Animal Model Analysis}

A 4-trait (DYS, PM, BWT, GL) threshold-linear animal model was determined to be the best model for the analysis of data available for this research because (1) female relationships were complete enough to warrant application of an animal model; and (2) the type of model adopted here is supported by previous publications where bivariate threshold-linear models were reported to be suitable for maternally influenced traits where categorical/liability (DYS, PM) and linear (BWT, GL) probability distributions must be addressed by the analysis procedure (Varona et al., 1999a,b; Ramirez-Valverde et al., 2001).

A detailed description of the multiple trait thresholdlinear animal model used in this research is given in the Appendix. Briefly, specific details unique to the analysis of this population follow. All 4 traits were analyzed simultaneously by using a multiple trait animal model.

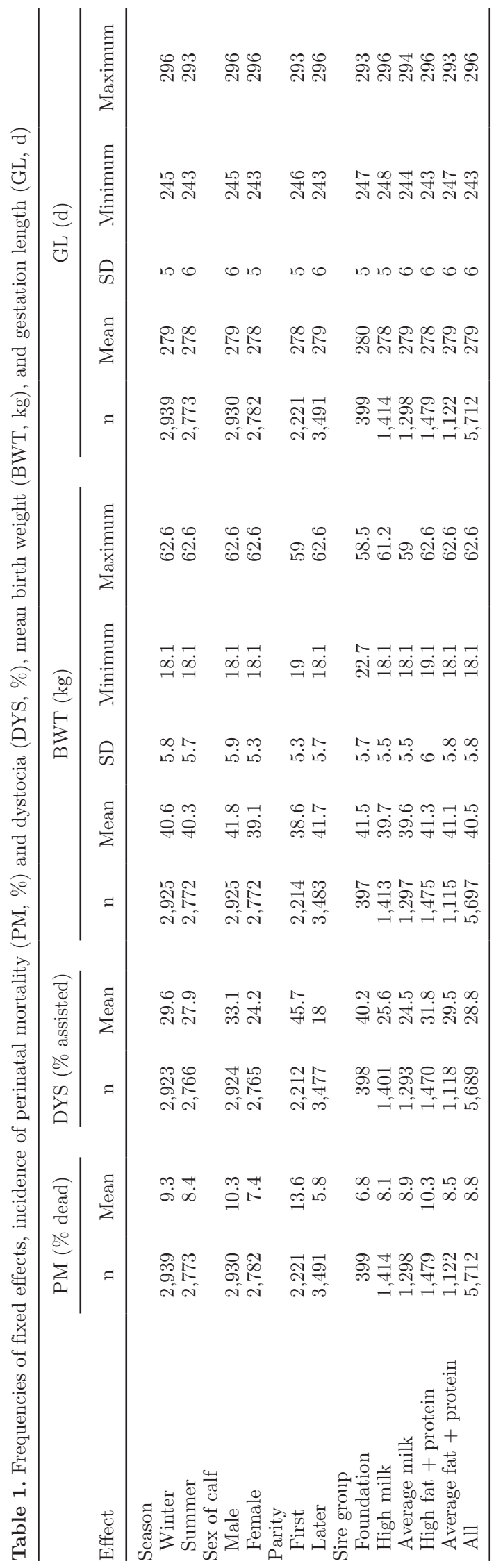


The effect for herd-year (1969-2004) was modeled as an uncorrelated random effect for DYS and PM, but it was modeled as fixed for BWT and GL. Modeling of herd-year as a random effect for DYS and PM was necessary after a preliminary analysis indicated we had encountered an extreme category problem by estimating the effect of herd-year as a fixed effect. The results were very similar except for a higher estimate of direct heritability for PM. Fixed herd-year with extreme categorical problem caused this heritability to be inflated. This method for handling the herd-year effect controlled any extreme categorical problems. The fixed effects included in the model were herd-year (for linear traits BWT and GL), season (winter or summer), sex of calf delivered (male or female), parity of dam (first or later), and sire group (the 5 groups defined in Data Preparation section above). The 4 traits included in the model were $\mathrm{CE}$ (categorical/ liability scale), PM (categorical/ liability scale), BWT (linear), and GL (linear). Each trait had random effects for direct genetic, maternal genetic, maternal permanent environment, and residual.

The computer program THRGIBBS1F90 (Lee et al., 2002; Misztal et al., 2002) was used to simultaneously fit a threshold model for DYS and PM and a linear model for BWT and GL. This program uses Gibbs sampling to evaluate the posterior density of (co)variance estimates. Flat, uninformative priors were used on all random effects. A single chain of 100,000 samples was generated. After burn-in of 10,000 samples, every 10th sample was stored to estimate the posterior mean and posterior standard deviation by using POSTGIBBSF90. This program summarizes Gibbs samples obtained from THRGIBBS1F90. It calculates posterior means and standard deviations, highest probability density, effective sample size, and autocorrelations between samples and draws graphs of chains and distributions of Gibbs samples (Tsuruta and Misztal, 2006).

\section{RESULTS}

Estimates of variance components for direct genetic [var (dir gen)] and direct (D) genetic-maternal (M) genetic covariances are given in Table 2. Two types of covariances are given: (1) within-trait $\operatorname{cov}\left(D_{i} M_{j}\right)$ for all $\mathrm{i}=\mathrm{j}=\mathrm{DYS}, \mathrm{PM}, \mathrm{BWT}$, and GL; for example, $\operatorname{cov}\left(\mathrm{D}_{\mathrm{DYS}}\right.$ $\left.\mathrm{M}_{\mathrm{DYS}}\right)$; and $(2)$ between-trait $\operatorname{cov}\left(\mathrm{D}_{\mathrm{i}} \mathrm{M}_{\mathrm{j}}\right)$ for all $\mathrm{i} \neq \mathrm{j}$; for example, $\operatorname{cov}\left(\mathrm{D}_{\mathrm{BWT}} \mathrm{M}_{\mathrm{GL}}\right)$. All $\operatorname{cov}\left(\mathrm{D}_{\mathrm{i}} \mathrm{MG}_{\mathrm{i}}\right)$ are negative within trait. They also decrease in order of size from DYS to PM to BWT to GL. Also, all $\operatorname{cov}\left(D_{i} M_{j}\right)$ are negative, with the exception of $\operatorname{cov}\left(\mathrm{D}_{\mathrm{DYS}} \mathrm{M}_{\mathrm{GL}}\right)$ and $\operatorname{cov}\left(\mathrm{D}_{\mathrm{BWT}} \mathrm{M}_{\mathrm{GL}}\right)$. These covariances for direct-maternal effects between traits are an added advantage of using the multi-trait model and have previously been ignored in the application of single-trait analyses.

Estimates of maternal genetic, maternal permanent environment, and residual variance are given in Table 2. All variances for DYS and PM are on the liability scale, whereas variances for BWT and GL are in the units of measure $\mathrm{kg}^{2}$ and $\mathrm{d}^{2}$, respectively.

\section{Heritability Estimates}

Table 3 gives the direct and maternal heritability estimates with their respective standard deviations (as well as genetic correlations to be discussed later) for all 4 traits. The direct heritability estimates for DYS, PM, BWT, and GL are 0.11 (0.04), 0.13 (0.05), 0.26 (0.04), and $0.51(0.05)$, respectively, whereas the maternal heritability estimates were $0.14(0.04), 0.15$ (0.03), 0.08 (0.01), and $0.08(0.02)$, respectively. It is important to note that all heritability estimates from this study for DYS and PM are on the liability scale, whereas heritability estimates for BWT and GL are on the observed scale.

\section{DISCUSSION}

In the following discussion, we compare estimates of parameters from this study with estimates for similar traits in the literature. Table 4 gives a detailed summary of direct and maternal heritability estimates for DYS, PM, BWT, and GL appearing in the literature. We emphasize details about the population (breed and parity), number of categories, scale of reported heritability estimates (liability [Liab] vs. observed [Obs]), and a brief description of the statistical model. Two of the articles cited in Table 4 share a surprising similarity in name and events with the 4 traits emphasized in this article. The common link between names of traits used by Hansen et al. (2004c), Jamrozik et al. (2005) and this article is as follows: $\mathrm{SB} / \mathrm{SB} / \mathrm{PM} ; \mathrm{CE} / \mathrm{CD} /$ DYS; CZ/CZ/BWT; and GL/GL/GL, where SB = stillbirths, $\mathrm{CE}=$ calving ease, $\mathrm{CD}=$ calving difficulty, and $\mathrm{CZ}=$ calf size.

\section{Dystocia}

The direct DYS heritability estimate of 0.11 is within the range of $0.004[\mathrm{Obs}]$ to 0.17 [Liab] reported in other studies (Luo et al., 1999, 2002; Steinbock et al., 2003; Hansen, 2004; Hansen et al., 2004c ; Jamrozik et al., 2005). The maternal DYS heritability estimate of 0.14 is also within the range of estimates reported in other studies where estimates ranged from 0.035[Liab] to 0.14[Obs] (Luo et al., 1999, 2002; Steinbock et al., 2003; 
Table 2. Posterior mean and standard deviation (PSD) for random year (YR), direct genetic variance (DG), and direct-maternal covariances (D_MG) effects and maternal genetic (MG), maternal permanent environment (MPE), and residual (R) variance for 4 calving traits

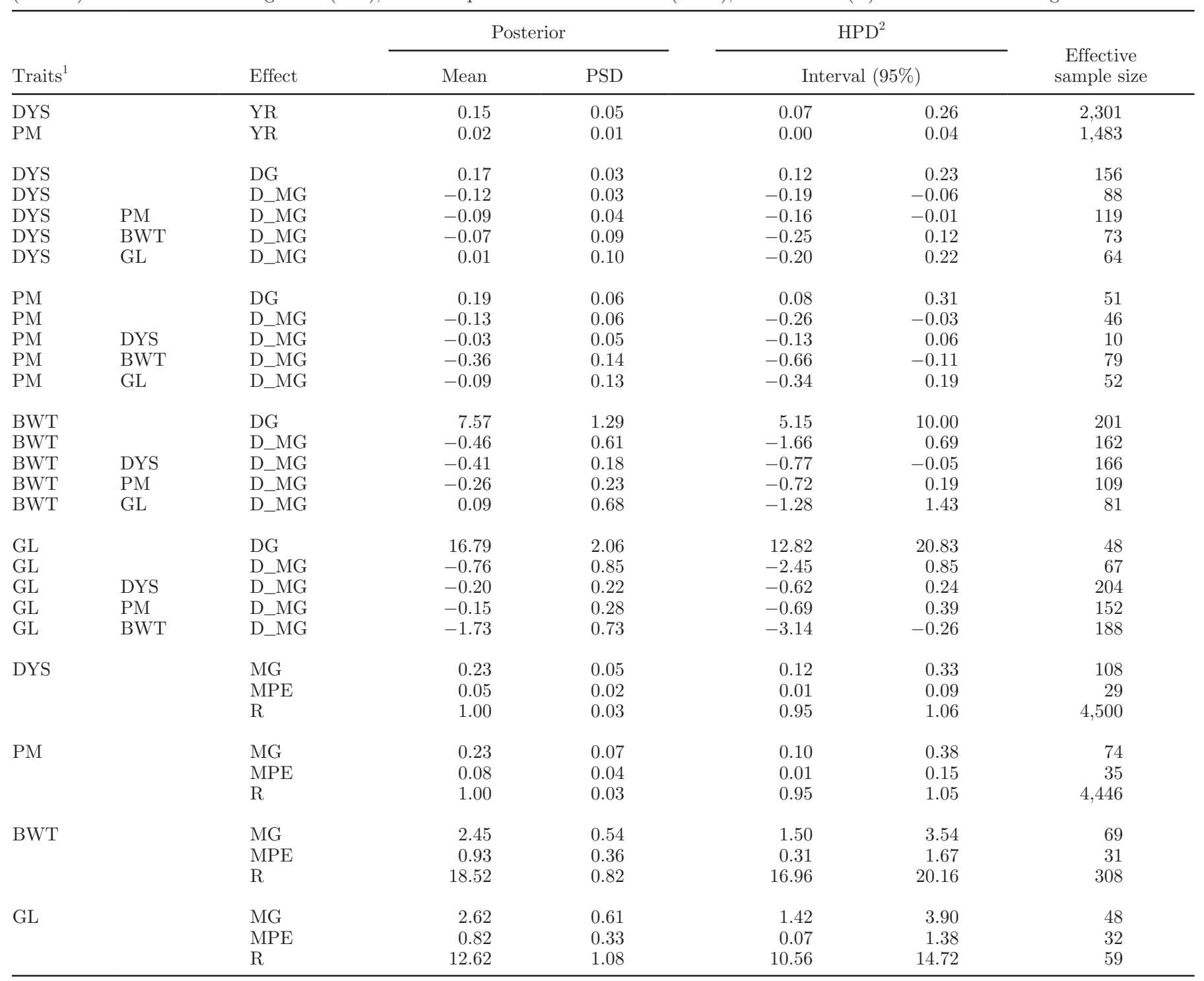

${ }^{1} \mathrm{DYS}=$ dystocia $\mathrm{PM}=$ perinatal mortality; $\mathrm{BWT}=$ birth weight $; \mathrm{GL}=$ gestation length.

${ }^{2} \mathrm{HPD}=$ highest posterior density.

Table 3. The posterior means of the Gibbs samples for heritability and genetic correlation estimates from the threshold-linear animal model; standard deviations are given as subscripts ${ }^{1}$

\begin{tabular}{|c|c|c|c|c|c|c|c|c|}
\hline Trait & $h^{2}$ & \multicolumn{7}{|c|}{ Genetic correlations } \\
\hline $\begin{array}{l}\text { DDYS } \\
\text { DPM } \\
\text { DBWT } \\
\text { DGL } \\
\text { MDYS } \\
\text { MPM } \\
\text { MBWT } \\
\text { MGL }\end{array}$ & $\begin{array}{l}0.11_{0.04} \\
0.13_{0.05} \\
0.26_{0.04} \\
0.51_{0.05} \\
0.14_{0.04} \\
0.15_{0.03} \\
0.08_{0.01} \\
0.08_{0.02}\end{array}$ & $0.67_{0.19}$ & $\begin{array}{l}0.73_{0.08} \\
0.57_{0.23}\end{array}$ & $\begin{array}{l}0.38_{0.11} \\
0.45_{0.12} \\
0.52_{0.07}\end{array}$ & $\begin{array}{l}-0.67_{0.11} \\
-0.24_{0.29} \\
-0.22_{0.13} \\
-0.06_{0.11}\end{array}$ & $\begin{array}{r}-0.48_{0.15} \\
-0.48_{0.16} \\
-0.29_{0.17} \\
-0.17_{0.14} \\
\quad 0.45_{0.16}\end{array}$ & $\begin{array}{r}-0.40_{0.13} \\
-0.31_{0.19} \\
-0.15_{0.15} \\
-0.41_{0.11} \\
0.27_{0.15} \\
-0.41_{0.14}\end{array}$ & $\begin{array}{r}-0.24_{0.17} \\
-0.12_{0.20} \\
0.08_{0.16} \\
-0.09_{0.13} \\
0.25_{0.15} \\
-0.31_{0.18} \\
0.56_{0.12}\end{array}$ \\
\hline
\end{tabular}

${ }^{1}$ Repeatability estimates: DYS $($ dystocia $)=0.14$, PM $($ perinatal mortality $)=0.18$, BWT $($ birth weight $)=0.29$, and GL $($ gestation length $)=$ 0.54. $\mathrm{D}=$ direct, $\mathrm{M}=$ maternal. 
Table 4. Estimates of direct $\left(h_{D}^{2}\right)$ and maternal $\left(h_{M}^{2}\right)$ heritability reported in the literature

\begin{tabular}{|c|c|c|c|c|c|c|c|c|c|c|}
\hline \multirow[b]{2}{*}{ Trait $^{1}$} & \multirow[b]{2}{*}{ Breed $^{2}$} & \multirow[b]{2}{*}{ Parity } & \multirow[b]{2}{*}{$\begin{array}{l}\text { Records } \\
\text { (n) }\end{array}$} & \multirow{2}{*}{$\begin{array}{l}\text { Number of } \\
\text { categories } \\
\text { (n) }\end{array}$} & \multirow[b]{2}{*}{ Scale } & \multicolumn{3}{|c|}{ Heritability } & \multirow[b]{2}{*}{$\begin{array}{l}\text { Statistical } \\
\text { model }^{3}\end{array}$} & \multirow[b]{2}{*}{ Notes } \\
\hline & & & & & & $h_{D}^{2}$ & $h_{M}^{2}$ & $\mathrm{r}_{\mathrm{DM}}$ & & \\
\hline $\mathrm{SB}^{4}$ & HF, ODBW & 1 & 391,186 & 2 & Liability & 0.1 & 0.13 & 0.05 & Th-S-MGS(GS) & \\
\hline $\mathrm{GL}^{5}$ & $\mathrm{HF}$ & 1 & 168,444 & Continuous & Observed & 0.42 & 0.07 & -0.13 & UL-S-MGS(GS) & \\
\hline SB & $\mathrm{HF}$ & 1 & 184,141 & 2 & Liability & 0.10 & 0.13 & 0.05 & UTH-S-MGS(GS) & \\
\hline CD & $\mathrm{HF}$ & 1 & 146,310 & 4 & Liability & 0.11 & 0.07 & 0.21 & UTH-S-MGS(GS) & \\
\hline $\mathrm{CZ}$ & $\mathrm{HF}$ & 1 & 152,741 & 4 & Liability & 0.22 & 0.04 & -0.11 & UTH-S-MGS(GS) & \\
\hline $\mathrm{SB}^{6}$ & HO & 1 & $1,048,145$ & 2 & Observed & 0.027 & & & UL-S & \\
\hline SB & HO & $>1$ & $2,779,295$ & 2 & Observed & 0.014 & & & UL-S & \\
\hline SB & HO & 1 & $1,048,145$ & 2 & Observed & & 0.047 & & UL-MGS & \\
\hline SB & $\mathrm{HO}$ & $>1$ & $2,779,295$ & 2 & Observed & & 0.007 & & UL-MGS & \\
\hline $\mathrm{GL}^{7}$ & $\mathrm{CA}-\mathrm{HO}$ & 1 & 29,907 & Continuous & Observed & 0.307 & 0.129 & 0.91 & $\mathrm{LAM}(\mathrm{GS})+\mathrm{SC}+\mathrm{A}$ & $240 \leq \mathrm{GL} \leq 300 \mathrm{~d}$ \\
\hline $\mathrm{CE}$ & CA-HO & 1 & 29,907 & 4 & Observed & 0.078 & 0.138 & 0.9 & $\mathrm{LAM}(\mathrm{GS})+\mathrm{SC}+\mathrm{A}$ & \\
\hline SB & $\mathrm{CA}-\mathrm{HO}$ & 1 & 27,643 & 2 & Observed & 0.016 & 0.035 & 0.31 & $\mathrm{LAM}(\mathrm{GS})+\mathrm{SC}+\mathrm{A}$ & \\
\hline $\mathrm{CZ}$ & CA-HO & 1 & 27,418 & 4 & Observed & 0.152 & 0.079 & 0.67 & $\mathrm{LAM}(\mathrm{GS})+\mathrm{SC}+\mathrm{A}$ & \\
\hline GL & $\mathrm{CA}-\mathrm{HO}$ & $>1$ & 16,124 & Continuous & Observed & 0.268 & 0.091 & & $\mathrm{LAM}(\mathrm{GS})+\mathrm{SC}+\mathrm{A}+\mathrm{PE}$ & \\
\hline $\mathrm{CE}$ & $\mathrm{CA}-\mathrm{HO}$ & $>1$ & 16,124 & 4 & Observed & 0.075 & 0.063 & & $\mathrm{LAM}(\mathrm{GS})+\mathrm{SC}+\mathrm{A}+\mathrm{PE}$ & \\
\hline SB & CA-HO & $>1$ & 15,416 & 2 & Observed & 0.012 & 0.017 & & $\mathrm{LAM}(\mathrm{GS})+\mathrm{SC}+\mathrm{A}+\mathrm{PE}$ & \\
\hline $\mathrm{CZ}$ & CA-HO & $>1$ & 15,371 & 4 & Observed & 0.109 & 0.05 & & $\mathrm{LAM}(\mathrm{GS})+\mathrm{SC}+\mathrm{A}+\mathrm{PE}$ & \\
\hline $\mathrm{CE}^{8}$ & $\mathrm{CA}-\mathrm{HO}$ & 1 & 129,756 & 4 & Snell-scores & 0.05 & 0.04 & -0.16 & BivarL(GS)-S-MGS & \\
\hline SB & CA-HO & 1 & 129,756 & 2 & Observed & 0.03 & 0.06 & -0.24 & BivarL(GS)-S-MGS & \\
\hline $\mathrm{CE}^{9}$ & CA-HO & 1 & 94,925 & 3 & Liability & 0.14 & 0.08 & 0.38 & Mt-th(GS)-S-MGS & Age at calving $\geq 22 \mathrm{mo}$ \\
\hline $\mathrm{CE}$ & $\mathrm{CA}-\mathrm{HO}$ & 2 & 94,925 & 3 & Liability & 0.1 & 0.04 & 0.35 & Mt-th(GS)-S-MGS & Age at calving $\geq 33 \mathrm{mo}$ \\
\hline $\mathrm{SB}^{10}$ & SLB & 1 & 411,409 & 2 & Observed & 0.038 & 0.028 & -0.11 & L-S-MGS & Adjusted for $\mathrm{CD}$ \\
\hline SB & SLB & 1 & 411,409 & 2 & Liability & 0.12 & 0.08 & -0.11 & Th(GS)-S-MGS & Adjusted for CD \\
\hline SB & SLB & 2 & 281,193 & 2 & Observed & 0.007 & 0.003 & -0.08 & L_S_MGS & Adjusted for CD \\
\hline SB & SLB & 2 & 281,193 & 2 & Liability & 0.04 & 0.02 & -0.08 & Th(GS)-S-MGS & Adjusted for CD \\
\hline CD & SLB & 1 & 411,409 & 2 & Observed & 0.062 & 0.048 & -0.09 & L-S-MGS & \\
\hline CD & SLB & 1 & 411,409 & 2 & Liability & 0.17 & 0.12 & -0.09 & Th(GS)-S-MGS & \\
\hline CD & SLB & 2 & 281,193 & 2 & Observed & 0.004 & 0.048 & 0.22 & L-S-MGS & \\
\hline CD & SLB & 2 & 281,193 & 2 & Liability & 0.07 & 0.04 & 0.03 & $\operatorname{Th}(\mathrm{GS})-\mathrm{S}-\mathrm{MGS}$ & \\
\hline $\mathrm{SB}^{11}$ & HF, ODBW & 2 & 108,071 & 2 & Liability & 0.05 & 0.005 & & BivarTh(GS)-S-MGS & $\mathrm{SB}, \mathrm{CD}$ \\
\hline CD & HF, ODBW & 2 & 89,936 & 4 & Liability & 0.082 & 0.04 & & BivarTh(GS)-S-MGS & $\mathrm{SB}, \mathrm{CD}$ \\
\hline $\mathrm{CZ}$ & HF, ODBW & 2 & 93,310 & 4 & Liability & 0.164 & 0.046 & & BivarTh(GS)-S-MGS & $\mathrm{SB}, \mathrm{CZ}$ \\
\hline \multicolumn{11}{|c|}{${ }^{1} \mathrm{SB}=$ stillbirths; $\mathrm{CD}=$ calving difficulty $; \mathrm{CE}=$ calving ease $; \mathrm{CZ}=$ calf size; $\mathrm{GL}=$ gestation length } \\
\hline \multicolumn{11}{|c|}{${ }^{2} \mathrm{HF}=$ Holstein-Friesian; $\mathrm{HO}=$ Holstein; ODBW = Original Danish Black and White; SLB = Swedish Holstein; CA-HO = Canadian Holstein. } \\
\hline \multicolumn{11}{|c|}{${ }^{3}$ Statistical model: $\mathrm{Th}=$ threshold; S-MGS $=$ sire-maternal grandsire; $\mathrm{GS}=$ Gibbs sampling; $\mathrm{U}=1$-trait; $\mathrm{L}=$ linear; $\mathrm{AM}=$ animal; $\mathrm{SC}=$ sire of calf; $\mathrm{A}=$ additive genetic; $\mathrm{PE}=$} \\
\hline \multicolumn{11}{|c|}{ permanent environment; BivarL = 2-trait linear. } \\
\hline \multicolumn{11}{|c|}{${ }^{5}$ Hansen et al. (2004c). } \\
\hline \multicolumn{11}{|c|}{${ }^{6}$ Harbers et al. $(2000)$. } \\
\hline \multicolumn{11}{|c|}{${ }^{7}$ Jamrozik et al. (2005). } \\
\hline \multicolumn{11}{|c|}{${ }^{8}$ Luo et al. (1999). } \\
\hline \multicolumn{11}{|c|}{${ }^{9}$ Luo et al. (2002). } \\
\hline \multicolumn{11}{|c|}{${ }^{10}$ Steinbock et al. (2003). } \\
\hline \multicolumn{11}{|c|}{${ }^{11}$ Hansen (2004). } \\
\hline
\end{tabular}


Hansen, 2004; Hansen et al., 2004c; Jamrozik et al., 2005). Typically, in the literature about DYS, the direct heritability estimate is about twice the magnitude of the maternal heritability estimate, and first-parity heritability is larger than that of later parities (See Table 4).

\section{Perinatal Mortality}

This direct PM heritability estimate of 0.13 is only slightly higher than the range of values from 0.007[Obs] to 0.12 [Liab] reported in other studies (Luo et al., 1999; Harbers et al., 2000; Steinbock et al., 2003; Hansen, 2004; Hansen et al., 2004a,c; Jamrozik et al., 2005). The maternal PM heritability estimate of 0.13 is at the upper end of the range of values from 0.005 [Liab] to 0.13[Liab] reported in other studies (Luo et al., 1999; Harbers et al., 2000; Steinbock et al., 2003; Hansen, 2004; Hansen et al., 2004a,c; Jamrozik et al., 2005). Typically, in literature about PM, the first-parity maternal heritability estimates are larger than those of later parities; however, some maternal heritability estimates are larger than the estimates for direct heritability.

\section{Birth Weight}

The direct and maternal BWT heritability estimates of 0.26 and 0.08 , respectively, are larger than the calf size estimates of $0.22[\mathrm{Liab}]$ and $0.04[\mathrm{Liab}]$ reported by Hansen et al. (2004c) and 0.16[Liab] and 0.05[Liab] reported by Hansen (2004). Hansen et al. (2004c) used a threshold model in first-parity cows on 4 categories of calf size to estimate direct and maternal heritabilities. Again, Hansen (2004) used 4 categories of calf size but in second-parity cows to estimate direct and maternal heritabilities. Jamrozik et al. (2005) used a linear model on 4 categories of calf size to estimate direct and maternal heritabilities of $0.15[\mathrm{Obs}]$ and $0.08[\mathrm{Obs}]$ for first-parity cows and 0.11 and 0.05 on later parity cows.

\section{Gestation Length}

The direct GL heritability estimate of 0.51 is larger than the range of direct heritability estimates from 0.27 to 0.44 (Hansen et al., 2004c; Jamrozik et al., 2005; A. M. Winkelman and R. J. Spelman, Livestock Improvement Corp. Ltd., Hamilton, New Zealand, personal communication, 2001). Winkelman and Spelman's work did not include a maternal effect among Ayrshire, Jersey, and Holstein cattle under selection for reduced gestation length in New Zealand. The maternal GL heritability estimate of 0.08 is nearly the same as the 0.07 reported by Hansen et al. (2004c), but smaller than estimates reported by Jamrozik et al. (2005) of 0.13 for first parity and 0.09 for later parities. Heritability estimates for GL based on service sire were reported at 47 and $33 \%$, respectively for heifers and cows, and $12 \%$ in both heifers and cows based on sire of the cow (Norman et al., 2009).

\section{Direct Genetic Correlations}

The direct genetic correlations between each of the direct effects were all positive, ranging from 0.38 $\left(\mathrm{r}_{\text {DDYS DGL }}\right)$ to 0.73 ( $\left.\mathrm{r}_{\text {DDYS DBWT }}\right)$. Hansen et al. (2004c) reported genetic correlations between direct genetic effects ranging from $0.18\left(\mathrm{r}_{\mathrm{DSB} D \mathrm{DGL}}\right)$ to 0.93 ( $\left.\mathrm{r}_{\mathrm{DCD}} \mathrm{DCZ}\right)$. Jamrozik at al. (2005) reported correlations ranging from $-0.40\left(\mathrm{r}_{\mathrm{DSB}} \mathrm{DCZ}\right)$ to $0.65\left(\mathrm{r}_{\mathrm{DCE}} \mathrm{DCZ}\right)$ in first-parity cows and a range of $-0.20\left(\mathrm{r}_{\mathrm{DCE} \text { DSB }}\right)$ to $0.59\left(\mathrm{r}_{\mathrm{DCE} \text { DCZ }}\right)$ in later parity cows.

\section{Maternal Genetic Correlations}

The maternal genetic correlations, between each of the maternal effects, range from -0.41 ( $\mathrm{r}_{\mathrm{MPM} \text { MBWT }}$ ) to 0.56 ( $\left.\mathrm{r}_{\mathrm{MBWT}} \mathrm{MGL}\right)$. We did not expect to find that 2 of the 6 maternal genetic correlations were negative. Traditional thinking is that only large BWT and long GL lead to PM, but closer attention needs to be paid to the relatively high incidence of PM in small calves or calves resulting from short GL. Evidence that the maternal breeding value for PM modifies or interacts with the maternal breeding for BWT and GL is suggested by the negative correlations of -0.41 between MPM and MBWT and -0.31 between MPM and MGL.

Hansen et al. (2004c) investigated 4 traits similar to the traits in this study (PM/SB, DYS/CD, BWT/CZ, GL/GL) with genetic correlations between maternal effects ranging from -0.04 ( $\left.\mathrm{r}_{\mathrm{MSB}} \mathrm{MGL}\right)$ to 0.62 ( $\left.\mathrm{r}_{\mathrm{MCD}} \mathrm{MSB}\right)$. Jamrozik et al. (2005) report first parity correlations ranging from $-0.52\left(\mathrm{r}_{\mathrm{MCD}} \mathrm{MSB}\right)$ to $0.58\left(\mathrm{r}_{\mathrm{MCD} \mathrm{MCZ}}\right)$ and later parity correlations ranging from $-0.03\left(\mathrm{r}_{\mathrm{MCD}} \mathrm{MGL}\right)$ to $0.67\left(\mathrm{r}_{\mathrm{MCZ} \mathrm{MGL}}\right)$.

\section{Genetic Correlations Between Direct and Maternal Effects}

All except one of the genetic correlations between direct and maternal effects were negative, and they ranged from -0.67 ( $\left.\mathrm{r}_{\text {DDYS MDYS }}\right)$ to 0.08 ( $\mathrm{r}_{\mathrm{DGL}}$ MDYS $)$. It is common for genetic correlations between direct and maternal effects to be negative. The estimates given by Hansen et al. (2004c) were not all negative, but they 
were all near zero, ranging from $-0.13\left(\mathrm{r}_{\mathrm{DGL}} \mathrm{MGL}\right)$ to 0.14 ( $\left.\mathrm{r}_{\text {DGL MSB }}\right)$. Jamrozik et al. (2005) did not report correlation between direct and maternal effects.

For many years, the only evaluation of calving performance available in the United States was CE. One would assume that sire selection for CE would help to limit PM. Contrary to this assumption, several reports have expressed concern that the incidence of PM in Holstein cattle is too high and is continuing to rise (Harbers et al., 2000; Meyer et al., 2001a; Luo et al., 2002; Steinbock et al., 2003; Hansen et al., 2004a,b). A valuable trait for both calving ease and PM is BWT, which the beef industry has been using for several years (Bertrand and Benyshek, 1987; Varona et al., 1999a,b; Ramirez-Valverde et al., 2001). Most dairy producers handle newborn calves at birth anyway and obtaining some measure of BWT would be reasonably simple. This study also shows high heritability of GL and its strong genetic correlations with the other 3 traits would also benefit the evaluation of PM and calving ease.

This study shows several very important results: (1) Both direct and maternal breeding values (BV) for DYS and PM are positively correlated: $\mathrm{r}_{\text {DDYS DPM }}=$ 0.67 and $\mathrm{r}_{\mathrm{MDYS} \text { MPM }}=0.45$, respectively; (2) Both BWT and GL have positive genetic correlations for direct and maternal BV: (a) $\mathrm{r}_{\text {DBWT DGL }}=0.52$; (b) $\mathrm{r}_{\text {MBWT MGL }}=$ 0.56 ; and (c) $\mathrm{r}_{\text {DBWT MGL }}=0.08$; (3) It is possible to complete a multiple-trait evaluation for prediction of BV for 2 categorical traits (DYS and PM on the liability scale) with 2 linear traits (BWT and GL on the observed scale); (4) This study provides evidence that BWT and GL have direct and maternal genetic components capable of providing supplemental information to prediction of BV for PM and DYS.

Ovulation rate and embryo survival have received considerable attention in polytocous species. In mice, evidence from both inbreeding and line-crossing studies showed that the genotype of the recipient mother accounted for much more of the genetic variation in prenatal mortality than did the genotype of the embryo (Bradford and Nott, 1969; Bradford, 1979; Moler et al., 1980). A study that specifically addressed the influence of maternal and embryonic genotypes on timing of implantation, conceptus growth, and gestation length concluded that timing of implantation and length of gestation vary within genetic lines, but delayed or advanced implantation was not the only factor that determined conceptus growth. An interaction between maternal and embryonic genotypes influenced rate of postimplantation development and survival to term, whereas the fetal genotype exert influence when birth takes place (Barkley and FitzGerald, 1990).

Elsewhere, interbreed egg transfer and crossbreeding experiments involving breeds with a wide range of gestation periods provide striking evidence about the role of fetal genotype in determining the duration of gestation in sheep. The fetus accounted for at least twothirds of genetic variation in gestation length in sheep (Bradford et al., 1972; Anderson et al., 1981). In addition, gestation length was a highly significant source of variation in BWT for natural and transfer Targhee lambs (Hinkelman et al., 1979). Obviously, dairy cattle are not a polytocous species, but these studies give reason to model DYS, PM, BWT, and GL jointly by using an animal model to simultaneously account for direct genetic BV, maternal genetic BV, and maternal permanent environment, to better understand the role and possible interaction between offspring, maternal, and paternal BV on the duration and successful outcome of pregnancy. They suggest that a genetic basis exists for the high incidence of stillbirths (Meyer et al., 2000) or perinatal mortality (Johanson and Berger, 2003) observed in fetuses at less than $280 \mathrm{~d}$ for Holsteins in the United States.

Gestational diabetes mellitus is known to increase prenatal mortality in women and requires specialized treatment (Crowther et al., 2005; Moss et al., 2007). This disease is a maternal environmental effect on GL. It causes prenatal mortality in humans, which suggests that further research should be directed toward identification of deficient uterine environments that can adversely affect an otherwise viable fetus, causing the fetus to initiate parturition early; that is, deficient uterine environments seem to be a possible explanation for the high incidence of stillbirths or PM associated with GL $<280 \mathrm{~d}$ in dairy field data (Meyer et al., 2000).

If and when data become available, a fifth trait that the authors feel should be investigated for inclusion in a calving performance evaluation is internally measured pelvic area (PA). Externally measured PA was valuable in predicting calving difficulty (Johanson and Berger, 2003). Internally measured pelvic area, however, would have less measurement error and conceptually may contribute to a causal explanation of maternal genetic and environment effects on DYS and PM. Unfortunately, internally measured PA is rarely measured in dairy cattle and measuring it would take more effort than measuring the other 4 traits studied here.

\section{CONCLUSIONS}

Variance components were estimated for both direct and maternal effects for 4 traits using a threshold (DYS, PM)-linear (BWT, GL) model in a multipletrait setting. Direct genetic, maternal genetic, and maternal permanent environment effects were identified as important sources of (co)variation. The direct genetic correlation between PM and DYS was estimated 
at 0.67 , whereas their maternal genetic correlation is 0.45. Therefore, single-trait sire selection can no longer be recommended because of the complex associations between direct and maternal genetic effects. With moderate genetic correlations between all 4 traits (DYS, PM, BWT, and GL), evidence exists that BWT and GL should be included with DYS and PM in an evaluation of calving performance. Because BWT and GL have larger heritability estimates than DYS and PM, selection on BWT and GL may indirectly reduce the incidence of DYS and PM. In addition to the biological interest for the traits included, some hidden and other unknown benefits were determined by the choice of traits and by having adopted a multiple-trait threshold-linear animal model. Previous research has clearly shown that pairing birth weight and CD in a bivariate linear-threshold model resulted in substantially higher accuracy of genetic prediction over a single-trait model (Varona et al., 1999a,b; Ramirez-Valverde et al., 2001). Therefore, greater accuracy of prediction of breeding values for DYS can be anticipated by having included BWT. Further investigation to determine the improvement in accuracy of predicting breeding values for PM by including BWT or GL is warranted.

\section{ACKNOWLEDGMENTS}

The availability of this data is credited to A. E. Freeman and the Iowa State University dairy breeding herd support staff for their 37 years of hard work. We appreciate the computer support of Mary Healey (Iowa State University, Ames) and her ability to organize the data necessary for this analysis.

\section{REFERENCES}

Anderson, G. B., G. E. Bradford, and P. T. Cupps. 1981. Length of gestation in ewes carrying lambs of two different breeds. Theriogenology 16:119-129.

Barkley, M. S., and R. FitzGerald. 1990. Influence of embryonic and maternal genotype on gestational events in the mouse. J. Reprod. Fertil. 89:285-291.

Berger, P. J. 1994. Genetic prediction for calving ease in the United States: Data, models, and use by the dairy industry. J. Dairy Sci. $77: 1146-1153$.

Berger, P. J., A. C. Cubas, K. J. Koehler, and M. H. Healey. 1992. Factors affecting dystocia and early calf mortality in Angus cows and heifers. J. Anim. Sci. 70:1775-1786.

Bertrand, J. K., and L. L. Benyshek. 1987. Variance and covariance estimates for maternally influenced beef growth traits. J. Anim. Sci. 64:728-734.

Bradford, G. E. 1979. Genetic variation in prenatal survival and litter size. J. Anim. Sci. 49:66-74.

Bradford, G. E., R. Hart, J. F. Quirke, and R. B. Land. 1972. Genetic control of the duration of gestation in sheep. J. Reprod. Fertil. 30:459-463.

Bradford, G. E., and C. F. G. Nott. 1969. Genetic control of ovulation rate and embryo survival in mice. II. Effects of crossing selected lines. Genetics 63:907-918.
Cole, J. B., R. C. Goodling Jr., G. R. Wiggans, and P. M. VanRaden. 2005. Genetic evaluation of calving ease for Brown Swiss, Jersey, and Holstein bulls from purebred and crossbred calvings. J. Dairy Sci. 88:1529-1539.

Cole, J. B., G. R. Wiggans, and P. M. VanRaden. 2007a. Genetic evaluation of stillbirth in United States Holsteins using a sire-maternal grandsire threshold model. J. Dairy Sci. 90:2480-2488.

Cole, J. B., G. R. Wiggans, P. M. VanRaden, and R. H. Miller. 2007b. Stillbirth (co)variance components for a sire-maternal grandsire threshold model and development of a calving ability index for sire selection. J. Dairy Sci. 90:2489-2496.

Crowther, C. A., J. E. Hiller, J. R. Moss, A. J. McPhee, W. S. Jeffries, and J. S. Robinson. 2005. Effect of treatment of gestational diabetes mellitus on pregnancy outcomes. N. Engl. J. Med. 352:2477-2486.

Dekkers, J. C. M. 1994. Optimal breeding strategies for dystocia. J. Dairy Sci. 77:3441-3453.

Dematawewa, C. M. B., and P. J. Berger. 1997. Effect of dystocia on yield, fertility, and cow losses and an economic evaluation of dystocia scores for Holsteins. J. Dairy Sci. 80:754-761.

Djemali, M., P. J. Berger, and A. E. Freeman. 1987. Ordered categorical sire evaluation for dystocia in Holsteins. J. Dairy Sci. 70:2374-2384

Hansen, M. 2004. Quantitative genetic analysis of mortality in Danish Holstein calves. Paper V:119-129. Genetic parameters of calving traits at first and second calving in Danish Holsteins. PhD Diss. Royal Vet. Agric. Univ., Frederiksberg, Denmark.

Hansen, M., M. S. Lund, J. Pedersen, and L. G. Christensen. 2004a. Genetic parameters for stillbirth in Danish Holstein cows using a Bayesian threshold model. J. Dairy Sci. 87:706-716.

Hansen, M., M. S. Lund, J. Pedersen, and L. G. Christensen. 2004c Gestation length in Danish Holsteins has weak genetic associations with stillbirth, calving difficulty, and calf size. Livest. Prod. Sci. 91:23-33.

Hansen, M., I. Misztal, M. S. Lund, J. Pedersen, and L. G. Christensen. 2004b. Undesired phenotypic and genetic trend for stillbirth in Danish Holsteins. J. Dairy Sci. 87:1477-1486.

Harbers, A., L. Segeren, and G. de Jong. 2000. Genetic parameters for stillbirth in the Netherlands. Proc. 2000 Interbull Mtg., Bled, Slovenia. Interbull Bull. 25:117-122.

Hinkelman, L. A., G. E. Bradford, E. J. Pollak, G. B. Anderson, and P. T. Cupps. 1979. An embryo transfer study of birth weight in Finnish Landrace and Targhee sheep. J. Anim. Sci. 48:298-306.

Jamrozik, J., J. Fatehi, G. J. Kistemaker, and L. R. Schaeffer. 2005. Estimates of genetic parameters for Canadian Holstein female reproduction traits. J. Dairy Sci. 88:2199-2208.

Johanson, J. M., and P. J. Berger. 2003. Birth weight as a predictor of dystocia and perinatal mortality in Holstein cattle. J. Dairy Sci. $86: 3745-3755$.

Johanson, J. M., P. J. Berger, B. W. Kirkpatrick, and M. R. Dentine. 2001. Twinning rates of North American Holstein sires. J. Dairy Sci. 84:2081-2088.

Lee, D., I. Misztal, J. K. Bertrand, and R. Rekaya. 2002. National evaluation for dystocia, gestation length and birth weight by linear and threshold model methodologies. J. Appl. Genet. 43:209216.

Luo, M. F., P. J. Boettcher, J. C. M. Dekkers, and L. R. Schaeffer. 1999. Bayesian analysis for estimation of genetic parameters of dystocia and stillbirth for Canadian Holsteins. J. Dairy Sci. 82:1848-1858. Online: http://www.adsa.org/manuscripts/jds8423.

Luo, M. F., P. J. Boettcher, L. R. Schaeffer, and J. C. M. Dekkers 2002. Estimation of genetic parameters of calving ease in first and second parities of Canadian Holsteins using Bayesian methods. Livest. Prod. Sci. 74:175-184.

McDermott, J. J., O. B. Allen, S. W. Martin, and D. M. Alves. 1992. Patterns of stillbirth and dystocia in Ontario cow-calf herds. Can. J. Vet. Res. 56:47-55.

Meijering, A. 1984. Dystocia and stillbirth in cattle-A review of causes, relations and implications. Livest. Prod. Sci. 11:143-177. 
Meyer, C. L., P. J. Berger, and K. J. Koehler. 2000. Interactions among factors affecting stillbirths in Holstein cattle in the United States. J. Dairy Sci. 83:2657-2663.

Meyer, C. L., P. J. Berger, K. J. Koehler, J. R. Thompson, and C. G. Sattler. 2001a. Phenotypic trends in incidence of stillbirths for Holsteins in the United States. J. Dairy Sci. 84:515-523.

Meyer, C. L., P. J. Berger, J. R. Thompson, and C. G. Sattler. 2001b. Genetic evaluation of Holstein sires and maternal grandsires in the United States for perinatal survival. J. Dairy Sci. 84:1246-1254.

Misztal, I., S. Tsuruta, T. Strabel, B. Auvray, T. Druet, and D. H. Lee. 2002. Blupf90 and related programs. Proc. 7th World Congr. Appl. Livest. Prod., Montpellier, France, Commun. No. 28-07.

Moler, T. L., S. E. Donahue, G. B. Anderson, and G. Bradford. 1980. Effects of maternal and embryonic genotype on prenatal survival in two selected mouse lines. J. Anim. Sci. 51:300-303.

Moss, J. R., C. A. Crowther, J. E. Hiller, K. J. Willson, and J. S. Robinson. 2007. Cost and consequences of treatment for mild gestational diabetes mellitus - Evaluation from the ACHOIS randomized trial. BMC Pregnancy Childbirth 7:27. doi:10.1186/14712393-7-27.

Norman, H. D., J. R. Wright, M. T. Kuhn, S. M. Hubbard, J. B. Cole, and P. M. VanRaden. 2009. Genetic and environmental factors that affect gestation length in dairy cattle. J. Dairy Sci. 92:2259-2269.

Ramirez-Valverde, R., I. Misztal, and J. K. Bertrand. 2001. Comparison of threshold and linear models for calving difficulty in beef cattle. J. Anim. Sci. 79:333-338.

Steinbock, L., A. Näsholm, B. Berglund, K. Johansson, and J. Philipsson. 2003. Genetic effects on stillbirth and calving difficulty in Swedish Holsteins at first and second calving. J. Dairy Sci. $86: 2228-2235$.

Tsuruta, S., and I. Misztal. 2006. THRGIBBS1F90 for estimation of variance components with threshold-linear models. Proc. 8th World Congr. Genet. Appl. Livest. Prod. Belo Horizonte, Brazil.

Van Tassell, C. P., G. R. Wiggans, and I. Misztal. 2003. Implementation of a sire-maternal grandsire model for evaluation of dystocia in the United States. J. Dairy Sci. 86:3366-3373.

Varona, L., I. Misztal, and J. K. Bertrand. 1999a. Threshold-linear versus linear-linear analysis of birth weight and calving ease using an animal model. I. Variance component estimation. J. Anim. Sci. 77:1994-2002.

Varona, L., I. Misztal, and J. K. Bertrand. 1999b. Threshold-linear versus linear-linear analysis of birth weight and calving ease using an animal model. II. Comparison of models. J. Anim. Sci. 77:2003-2007.

Wiggans, G. R., I. Misztal, and C. P. Van Tassell. 2003. Dystocia (co)variance components for a sire-maternal grandsire threshold model. J. Dairy Sci. 86:1845-1848.

\section{APPENDIX}

The multiple trait threshold-linear animal model allows different models for different traits. The model for BWT and GL has 4 random effects: a) direct genetic; b) maternal genetic; c) maternal permanent environment; and d) random residual. The model for DYS and PM has 5 random effects; 4 as contained in the model for BWT and GL: a) direct genetic; b) maternal genetic; c) maternal permanent environment; and d) random residual. The fifth additional random effect, defined as random herd-year effect, is needed to address the "extreme category" problem encountered in this analysis of binomial data and described earlier. Herd-year effects are fit as an uncorrelated random effect. Furthermore, it is important to estimate genetic and environmental effects separately and as completely as possible.
Therefore, maternal permanent environment effects are estimated as uncorrelated random effects.

The equations and assumptions for a 4 trait threshold-linear animal model are described in this section. The model assumes a linear model for BWT $\left(\mathbf{y}_{\mathbf{B W T}}\right)$ and gestation length $\left(\mathbf{y}_{\mathrm{GL}}\right)$, the liability for dystocia $\left(\ell_{D Y S}\right)$, and perinatal mortality $\left(\ell_{P M}\right)$.

$$
\left[\begin{array}{c}
\mathrm{y}_{B W T} \\
\mathrm{y}_{G L} \\
\ell_{D Y S} \\
\ell_{P M}
\end{array}\right]=\left[\begin{array}{c}
\mathrm{X}_{1} \boldsymbol{\beta}_{B W T}+\mathrm{X}_{2} \mathrm{~h}_{B W T}+\mathrm{Z}_{2} \mathrm{u}_{d_{B W T}}+\mathrm{Z}_{3} \mathrm{u}_{m_{B W T}}+\mathrm{Z}_{4} \mathrm{u}_{p e_{B W T}} \\
\mathrm{X}_{1} \boldsymbol{\beta}_{G l}+\mathrm{X}_{2} \mathrm{~h}_{G L}+\mathrm{Z}_{2} \mathrm{u}_{d_{G L}}+\mathrm{Z}_{3} \mathrm{u}_{m_{G L}}+\mathrm{Z}_{4} \mathrm{u}_{p e_{G L}} \\
\mathrm{X}_{1} \boldsymbol{\beta}_{D Y S}+\mathrm{Z}_{1} \mathrm{~h}_{D Y S}+\mathrm{Z}_{2} \mathrm{u}_{d_{D Y S}}+\mathrm{Z}_{3} \mathrm{u}_{m_{D Y S}}+\mathrm{Z}_{4} \mathrm{u}_{p e_{D Y S}} \\
\mathrm{X}_{1} \boldsymbol{\beta}_{P M}+\mathrm{Z}_{1} \mathrm{~h}_{P M}+\mathrm{Z}_{2} \mathrm{u}_{d_{P M}}+\mathrm{Z}_{3} \mathrm{u}_{m_{P M}}+\mathrm{Z}_{4} \mathrm{u}_{p e_{P M}}
\end{array}\right],
$$

\section{$\mathbf{I} \otimes \mathbf{R}$}

where $\mathrm{I}$ is an identity matrix and $\mathrm{R}$ is the residual (co) variance matrix; $\boldsymbol{\beta}_{\mathrm{BWT}}, \boldsymbol{\beta}_{\mathrm{GL}}, \boldsymbol{\beta}_{\mathrm{DYS}}, \boldsymbol{\beta}_{\mathrm{PM}}, \mathbf{h}_{\mathrm{BWT}}$, and $\mathbf{h}_{\mathrm{GL}}$ are fixed effects; $\mathbf{X}_{1}, \mathbf{X}_{2}, \mathbf{Z}_{1}, \mathbf{Z}_{2}, \mathbf{Z}_{3}$, and $\mathbf{Z}_{4}$ are known matrices linking the vector of $\left[\mathbf{y}_{\mathrm{BWT}}: \mathbf{y}_{\mathrm{GL}}: \ell_{D Y S}: \ell_{P M}\right]$ with effects in the model. Prior distribution for season, sex of calf, parity, and sire group effects was assumed to be flat.

Prior distribution for herd-year effects was assumed to be flat for $\mathbf{h}_{\mathrm{BWT}}$ and $\mathbf{h}_{\mathrm{GL}}$. Prior distribution for herdyear was assumed to be multivariate normal for $\mathbf{h}_{\text {DYS }}$ and $\mathbf{h}_{\mathrm{PM}}$.

$$
\mathrm{f}\left(\mathbf{h}_{\mathrm{DYS}}, \mathbf{h}_{\mathrm{PM}}\right) \sim N(0, \mathbf{I} \otimes \mathbf{T}),
$$

where $\mathbf{T}$ is a $2 \times 2$ (co)variance matrix between herdyear effects. Similarly, for direct and maternal breeding values

$$
\mathrm{f}\left(\mathbf{u}_{\mathrm{d}_{\mathrm{BWT}}}, \mathbf{u}_{\mathrm{d}_{\mathrm{GL}}}, \mathbf{u}_{\mathrm{d}_{\mathrm{DYS}}}, \mathbf{u}_{\mathrm{d}_{\mathrm{PM}}}\right) \sim N(0, \mathbf{A} \otimes \mathbf{G}),
$$

where $\mathbf{A}$ is numerator relationship matrix and $\mathbf{G}$ is genetic covariance matrix.

The equations and assumptions used in this research are an extension of the equations given by Varona et al. (1999a) for a bivariate threshold-linear animal model with specific application to genetic evaluations in beef cattle for BWT and CD. Following simulation and model validation Varona et al. (1999b) concluded "the multiple-trait animal model provides good properties in terms of prediction of future record or progeny performance in relation to the single-trait animal model." Later, Ramirez-Valverde et al., (2001) used a combination of simulated populations and a representative sample of beef cattle field data containing first-parity 
BWT and CD to find that the bivariate threshold-linear animal model gave greater accuracy of predicted breeding values than sire and maternal grandsire models.

Let $\hat{\sigma}_{p_{1}}^{2}=\hat{\sigma}_{h_{i}}^{2}+\hat{\sigma}_{D G_{i}}^{2}+\hat{\sigma}_{M G_{i}}^{2}+\hat{\sigma}_{M P E_{i}}^{2}+\hat{\sigma}_{e_{i}}^{2}$ for $i=$ DYS, PM be the phenotypic variance for DYS and PM, and $\hat{\sigma}_{p_{2}}^{2}=\hat{\sigma}_{D G_{i}}^{2}+\hat{\sigma}_{M G_{i}}^{2}+\hat{\sigma}_{M P E_{i}}^{2}+\hat{\sigma}_{e_{i}}^{2}$ be the phenotypic variance for $i=\mathrm{BWT}$ and GL.
Direct heritability was estimated as $\hat{\mathbf{h}}_{d_{i}}^{2}=\hat{\sigma}_{D G_{i}}^{2} / \hat{\sigma}_{p_{1}}^{2}$ and maternal heritability was estimated as $\hat{\mathbf{h}}_{M G_{i}}^{2}=\hat{\sigma}_{M G_{i}}^{2} / \hat{\sigma}_{p_{1}}^{2}$ for $i=$ DYS and PM.

Direct heritability was estimated as $\hat{\mathbf{h}}_{d_{i}}^{2}=\hat{\sigma}_{D G_{i}}^{2} / \hat{\sigma}_{p_{2}}^{2}$ and maternal heritability was estimated as $\hat{\mathbf{h}}_{M G_{i}}^{2}=\hat{\sigma}_{M G_{i}}^{2} / \hat{\sigma}_{p_{2}}^{2}$ for $i=$ BWT and GL. 